\title{
High Corticosterone Levels in Prenatally Stressed Rats Predict Persistent Paradoxical Sleep Alterations
}

\author{
C. Dugovic, ${ }^{1}$ S. Maccari, ${ }^{2}$ L. Weibel, ${ }^{3}$ F. W. Turek, ${ }^{3}$ and O. Van Reeth ${ }^{3}$ \\ ${ }^{1}$ Department of Neuropsychopharmacology, Janssen Research Foundation, 2340 Beerse, Belgium, 2Laboratoire \\ Neurosciences du Comportement, Université de Lille, 59655 Villeneuve d'Ascq, France, and ' ${ }^{2}$ Center for the Study of \\ Biological Rhythms, School of Medicine, Erasme Hospital, Université Libre de Bruxelles, 1070 Brussels, Belgium
}

Prenatal stress predisposes rats to long-lasting disturbances that persist throughout adulthood (e.g., high anxiety, dysfunction of the hypothalamo-pituitary-adrenal axis, and abnormal circadian timing). These disturbances parallel to a large extent those found in depressed patients, in which hypercortisolemia and sleep alterations may be related to stress-inducing events. We studied sleep-wake parameters in control and prenatally stressed adult rats (3-4 months old) and examined possible relationships with their corticosterone levels (determined at 2 months of age). Under baseline conditions, prenatally stressed rats showed increased amounts of paradoxical sleep, positively correlated to plasma corticosterone levels. Other changes include increased sleep fragmentation, total light slow-wave sleep time, and a slight decrease in the percentage of deep slow-wave sleep relative to total sleep time. During recovery sleep from acute restraint stress, all sleep changes persisted and were correlated with stress-induced corticosterone secretion. High corticosterone levels under baseline conditions as well as an acute stress challenge may thus predict long-term sleep-wake alterations in rats. Taken together with other behavioral and hormonal abnormalities in prenatally stressed animals, the pronounced changes in sleep-wake parameters that are similar to those found in depressed patients suggest that prenatal stress may be a useful animal model of depression.

Key words: prenatal stress; sleep-wake parameters; paradoxical sleep; corticosterone; restraint stress; rat
Prenatal stress in rats can lead to profound behavioral and endocrine abnormalities in adult animals. Many of these abnormalities parallel those found in human depression, suggesting that the prenatally stressed (PNS) rat may be an animal model for depression. For example, PNS rats exhibit "behavioral despair" (Alonso et al., 1997) in the forced swimming test, a proposed measure of "learned helplessness" in rodents (Porsolt et al., 1977). They also show increased reactivity to novelty (open field and Y maze) and a higher propensity to self-administer amphetamine (Deminière et al., 1992), indicating an enhanced emotional reactivity (Joffe, 1978; Vallée et al., 1997; Weinstock, 1997) and anxiety (Vallée et al., 1997). In addition, feedback inhibition of the hypothalamopituitary-adrenal (HPA) axis by circulating glucocorticoids is impaired in both PNS rats and depressed patients (Holsboer et al., 1984; Maccari et al., 1995; Barbazanges et al., 1996; Modell et al., 1997; Vallée et al., 1997; Plotsky et al., 1998). Abnormalities in a variety of overt circadian rhythms, including the cortisol rhythm, have been documented in depressed patients (WirzJustice, 1995; Rosenwasser and Wirz-Justice, 1997), and we have recently discovered that PNS adult rats also show disturbances in circadian rhythms (locomotor activity, corticosterone secretion) that are consistent with those observed in depressed humans (Koehl et al., 1997, 1999; Van Reeth et al., 1998).

Received Feb. 23, 1999; revised June 21, 1999; accepted July 20, 1999.

This work was supported by the Belgian Fonds National de la Recherche Scientifique and Fonds de la Recherche Scientifique Médicale, a NATO collaborative research grant (960771), and a Commissariat Général aux Relations Internationales-Institut National de la Santé et de la Recherche Médicale grant to O.V.R. and S.M. We thank R. Biermans, A. Heylen, and W. Van Den Broeck for their skillful technical assistance.

Correspondence should be addressed to Dr. Olivier Van Reeth, Center for the Study of Biological Rhythms, School of Medicine-Université Libre de Bruxelles Hôpital Erasme, Route de Lennik, 808, 1070 Brussels, Belgium.

Copyright (C) 1999 Society for Neuroscience $0270-6474 / 99 / 198656-09 \$ 05.00 / 0$
One of the hallmarks of human depression is an alteration in the sleep-wake cycle, including a shortened rapid eye movement (REM) sleep latency, an increase in the amount and frequency of REM sleep during the first part of the night, increased sleep fragmentation, and a decrease in the amount of slow-wave sleep (Kupfer and Reynolds, 1992). In the present study we sought to determine whether prenatal stress could have long-term effects on the sleep-wake cycle in adult rats. On the basis of previous findings on the influence of stress on sleep regulation (Cespuglio et al., 1995), the sleep patterns of PNS rats in response to acute stress were assessed and compared to controls. In view of the established correlation between HPA axis disturbances and some behavioral abnormalities in adult PNS rats (Vallée et al., 1997), we evaluated possible correlations between sleep-wake parameters and plasma corticosterone levels under both baseline and acute stress conditions.

Our results demonstrate pronounced effects of prenatal stress on sleep in adult rats that parallel, to some extent, changes in sleep architecture found in depressed patients. These data add further support for the use of the PNS rat as an animal model for depression. The persistence of sleep abnormalities and other depressive-like symptoms even after termination of the adverse stimulus in the prenatal stress model makes it a particularly attractive model for the design and testing of new therapeutical strategies in mood and sleep disorders.

\section{MATERIALS AND METHODS}

Animals. Adult virgin Sprague Dawley female rats (IFFA Credo, Brussels, Belgium) weighing $\sim 240$ gm were first group-housed (10 per cage, size $\approx 60 \times 80 \mathrm{~cm}$ ) for $10 \mathrm{~d}$ in order to coordinate their estrous cycle, and then individually housed for a full estrous cycle $(4 \mathrm{~d})$ in the presence of a sexually experienced male Sprague Dawley rat weighing $\sim 400 \mathrm{gm}$. Mating was performed in a separate and very quiet animal room. Males 
were then removed from the cages, and pregnant females were randomly assigned to PNS or control (CONT) groups, individually housed in plastic cages, allowed ad libitum access to food and water, and maintained on a $12 \mathrm{hr}$ light/dark cycle (LD; lights on, 8:30 A.M. to 8:30 P.M.; light intensity, $\sim 100$ lux $)$ at constant room temperature $\left(22 \pm 2^{\circ} \mathrm{C}\right)$ and humidity $(60 \%)$. After birth, pups were raised with their mother in a separate room. All animal procedures were approved by the institutional animal care and use committee.

Prenatal stress procedure. Prenatal stress was performed daily during the last week of pregnancy until delivery. Pregnant females were individually restrained three times a day (at 9:00 A.M., 12:00 A.M., and 5:00 P.M.) for $45 \mathrm{~min}$ in transparent plastic cylinders $(7 \mathrm{~cm}$ diameter; $19 \mathrm{~cm}$ long) and exposed to bright light (1500 lux). Control pregnant females were left undisturbed in their home cages. Offspring were weaned $21 \mathrm{~d}$ after birth and housed in same-sex groups of four until the age of 2 months. The animals tested were derived from a total of five litters per condition (five CONT, five PNS). Only litters of 8-13 pups with similar numbers of males and females were used for the study. Only one or two male pups per litter were studied as adults to eliminate any possible "litter effects" (Chapman and Stern, 1979) on the measured variables. Experiments were performed on eight male CONT and eight PNS rats. No female rats were included to avoid the influence of the estrous cycle on spontaneous sleep patterns (Schwierin et al., 1998).

Blood sampling and corticosterone measurements. At 2 months of age blood samples were collected (via the tail vein) three times between 9:30 and 11:30 A.M. Rats were moved to an adjacent room and were placed individually in a restraint transparent tube, and blood was collected quickly $(<2 \mathrm{~min})$ to determine basal corticosterone levels. The second sampling was performed $20 \mathrm{~min}$ after restraint stress was initiated. The rats were then returned to their home cages with their usual partners, until the last blood sampling was performed $60 \mathrm{~min}$ after the initiation of the stress procedure. Restraint was performed in plastic cylinders identical to those used for the prenatal stress procedure. Blood corticosterone levels were determined by radioimmunoassay using a highly specific corticosterone antiserum (ICN Biomedicals, Cleveland, OH) with a detection threshold of $0.1 \mu \mathrm{g} / 100 \mathrm{ml}$. The interassay and intra-assay variations were, respectively, 6 and $3.5 \%$ at a mean value of $1.5 \mathrm{ng} /$ tube and 6.8 and $4 \%$ at a mean value of $10 \mathrm{ng} /$ tube.

Electrode implantation and EEG sleep recording. One month after the restraint stress procedure, the rats were moved to a sleep recording room. The animals were implanted under deep anesthesia (Thalamonal; $1 \mathrm{ml}$, s.c.) with chronic electrodes for polygraphic recordings of frontoparietal electroencephalogram (EEG), electrooculogram (EOG), and nuchal electromyogram (EMG). All electrodes were attached to a microconnector and fixed to the skull with dental cement. After surgery, the rats were individually housed in Plexiglas cages $(30 \mathrm{~cm}$ diameter, $40 \mathrm{~cm}$ high), maintained under similar environmental conditions as before and left undisturbed for 2 weeks. The animals were then habituated to the sleep recording procedure for the next $14 \mathrm{~d}$. In their home cages and in the same room, the rats were connected with a cable to a rotating swivel allowing free movements, and EEG, EOG, and EMG activities were recorded on a polygraph (EEG-4414 A/K; Nihon-Khoden) with an output connected to a computer for on-line spectral analysis of the EEG. Habituation consisted of two recording sessions for $8 \mathrm{hr}$ and two sessions of $24 \mathrm{hr}$.

At the end of the habituation period, sleep was recorded for a period of $24 \mathrm{hr}$, beginning at the onset of the light phase. Over the next month, when the rats were 4 months of age, sleep was recorded during two additional sessions. In the first of these sessions, sleep was recorded for $22 \mathrm{hr}$ starting $2 \mathrm{hr}$ after light onset, and served as a baseline for the effects of a restraint stress procedure on sleep 2 d later. Restraint, for $1 \mathrm{hr}$ beginning $1 \mathrm{hr}$ after lights on, was performed on a table next to the home cage, under bright light (1500 lux) in plastic cylinders identical to those used for the prenatal stress procedure. Polygraphic recordings were again obtained for the following $22 \mathrm{hr}$ time interval.

Data analysis. Polygraphic recordings were visually scored by $30 \mathrm{sec}$ epochs. Those epochs were classified as being either wake (W), light slow-wave sleep (SWS1), deep slow-wave sleep (SWS2), or paradoxical sleep (PS), as described earlier (Dugovic et al., 1989). Briefly, the different vigilance states were characterized as follows: W, low-voltage fast EEG activity, high EMG activity, and numerous eye movements; SWS1, high-voltage slow cortical waves interrupted by low-voltage fast waves, and reduced EMG activity; SWS2, continuous high-amplitude slow-wave activity in EEG, very low EMG activity, and no EOG activity; and PS, low-voltage fast cortical waves with a regular theta rhythm, absence of muscular tone, and presence of rapid eye movements. Scores were entered into a computer that calculated various sleep-wake parameters: amount of time spent in the four vigilance states and number and duration of episodes for each state. Sleep-wake parameters were analyzed over 2 and $4 \mathrm{hr}$ time intervals, as well as over the total light and dark phases. The duration of time spent in the different states of vigilance was expressed in minutes as well as a percentage of recording time.

All software routines for EEG spectral analysis were written using a VAX lab 1.4 Scientific Library. The EEG signal was high-pass frequency filtered at $1 \mathrm{~Hz}$ and low-pass frequency filtered at $35 \mathrm{~Hz}$. The analog signal was digitized at a sampling rate of 102.4 per sec with a 12 bit resolution, to yield epochs of $5 \mathrm{sec}$ duration composed of 512 samples. A spectral window filter (Welch) was applied to the digitized signal. Every $5 \mathrm{sec}$, Fast Fourier Transformations were performed on these 512 data points within the frequency range of $1-32 \mathrm{~Hz}$ and with a frequency resolution of $0.2 \mathrm{~Hz}$. EEG power spectra in the different states of vigilance were calculated by computing average power density values in each frequency bin per $2 \mathrm{hr}$ time interval.

Parameters of the sleep-wake cycle of CONT animals were compared with those of the PNS animals under baseline conditions. The effects of restraint on sleep in the CONT and PNS animals were also analyzed to determine whether the two groups responded differentially to the stress procedure. Correlations between any sleep-wake differences at the age of 3-4 months and basal and stress-induced corticosterone secretion obtained at 2 months of age were assessed.

Sleep data were analyzed with factorial ANOVA at different times across the entire recording period. Subsequently, differences between groups were assessed by means of the unpaired two-tailed Student's $t$ test. Within each group, differences between baseline and recovery from $1 \mathrm{hr}$ restraint stress were assessed by means of paired two-tailed Student's $t$ tests for the sleep-wake parameters and by the Wilcoxon signed-rank test for the EEG power spectral values. ANOVA was used to compare values of plasma corticosterone levels in response to the restraint procedure between the two groups of rats (factorial ANOVA, treatment effect) and whether there was an interaction between treatment (prenatal stress) and the time of blood sampling. Relationships between the different sleepwake parameters and corticosterone levels were assessed by Pearson's correlation analyses. The area under the curve (AUC) was calculated by the use of the trapezoidal rule. All values are expressed as mean \pm SEM.

\section{RESULTS}

\section{Basal and stress-induced corticosterone secretion}

Mean $( \pm$ SEM) basal corticosterone levels in CONT $(0.38 \pm 0.06$ $\mu \mathrm{g} / 100 \mathrm{ml})$ and PNS $(1.70 \pm 0.83 \mu \mathrm{g} / 100 \mathrm{ml})$ animals were not significantly different (ANOVA, $F_{(1,14)}=2.434 ; p=0.1411$ ). Stress-induced corticosterone secretion differed between the two groups (ANOVA, interaction treatment $\times$ time, $F_{(2,28)}=5.591$; $p=0.0091)$. Higher corticosterone values were observed in PNS rats, both $20 \mathrm{~min}(\mathrm{CONT}, 20.00 \pm 3.46 \mu \mathrm{g} / 100 \mathrm{ml}$; PNS, $39.13 \pm$ $3.40 \mu \mathrm{g} / 100 \mathrm{ml}$; group effect, $\left.F_{(1,14)}=15.208 ; p=0.0016\right)$ and 60 min after the initiation of the stress procedure (CONT, $6.38 \pm$ $0.79 \mu \mathrm{g} / 100 \mathrm{ml}$; PNS, $19.38 \pm 4.59 \mu \mathrm{g} / 100 \mathrm{ml}$; group effect, $F_{(1,14)}$ $=7.759 ; p=0.0147$ ). Furthermore, the AUC (micrograms per $100 \mathrm{ml} \times 1 \mathrm{hr}$ ) for stress-induced plasma corticosterone levels was significantly larger in PNS $(1578 \pm 133 \mu \mathrm{g} / 100 \mathrm{ml} \times 1 \mathrm{hr})$ compared to CONT $(731 \pm 112 \mu \mathrm{g} / 100 \mathrm{ml} \times 1 \mathrm{hr})$ rats $(t=4.841$; $p=0.0003$ ) (Fig. 1).

\section{Baseline EEG sleep and correlations with basal and stress-induced corticosterone secretion}

Prenatal stress induced substantial changes in both the structure and the continuity of sleep in adult rats. A plot of the distribution of vigilance states in $4 \mathrm{hr}$ bins over the $24 \mathrm{hr}$ LD cycle revealed that PS was the most altered state (Fig. 2). Compared to CONT rats, PNS rats showed increased total PS time, as well as an increase in the percentage of total sleep time in PS, during both the light and dark phases (Table 1). The increase in time spent in PS over the $24 \mathrm{hr}$ recording period $(+33 \%$; $p<0.0001)$ was caused by an increase in the number of PS episodes $(+31 \%$ over 


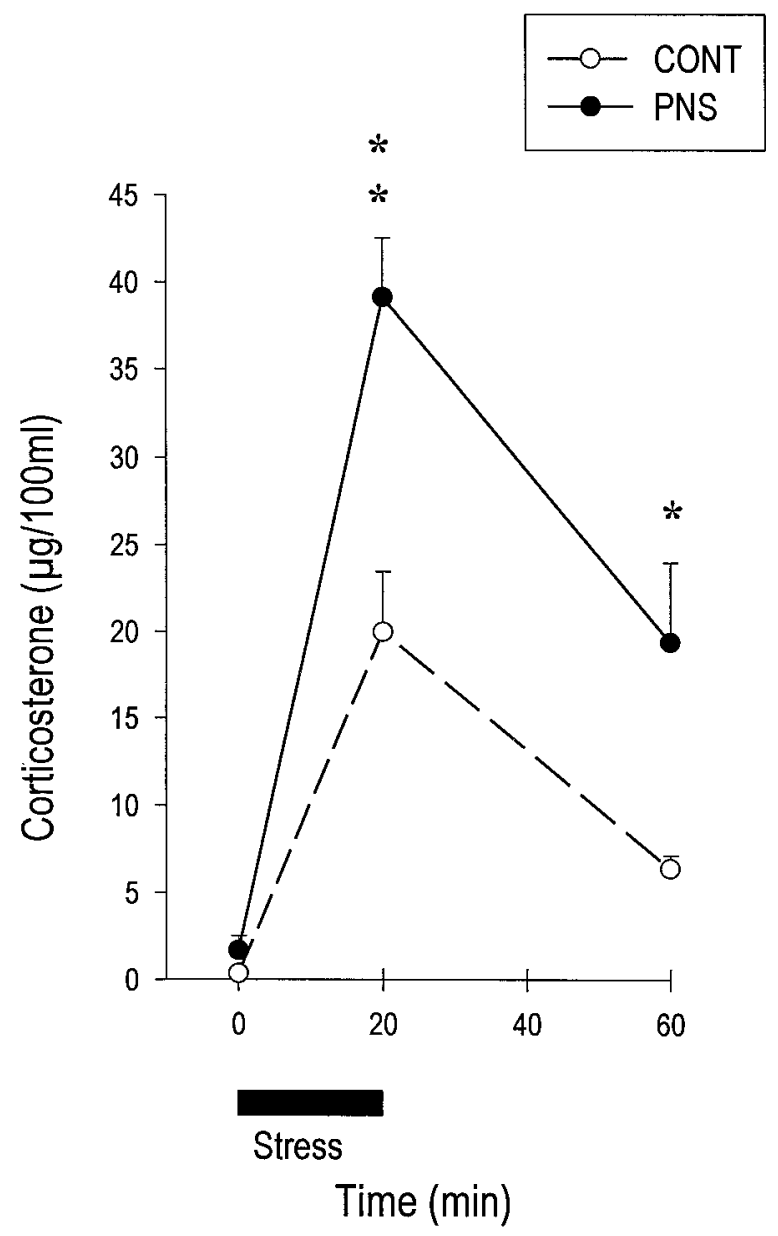

Figure 1. Corticosterone secretion induced by $20 \mathrm{~min}$ restraint stress (black line of abscisse) in control (CONT) and prenatally stressed (PNS) rats. At 2 months of age, PNS male rats showed higher corticosterone levels both 20 and $60 \mathrm{~min}$ after initiation of the restraint procedure. No change was observed in basal corticosterone levels between the two groups. ${ }^{*} p<0.05 ;{ }^{* *} p<0.01$ (ANOVA).

the $24 \mathrm{hr}$ interval; $p=0.0014$ ) (Fig. 3), whereas the mean duration of PS episodes remained the same in the two groups.

In addition to the clear effects on PS, prenatal stress also induced an increase in total SWS1 time that was restricted to the dark phase $(+33 \% ; p=0.0007)$. Although the total SWS2 time was not significantly changed, the percentage of total sleep time in SWS2 was significantly decreased in both the light and dark phases in PNS animals (Fig. 2, Table 1). In addition, sleep was more fragmented during the dark phase in PNS animals, as indexed by a larger number of episodes in each vigilance state (Fig. 3) and a shorter duration of W episodes (CONT, $4.4 \pm 0.2$; PNS, $3.5 \pm 0.1 ; p=0.0007)$. This resulted in less time spent in $\mathrm{W}$ $(-8 \% ; p=0.0011)$ during the dark phase (Table 1).

Quantitative analysis of EEG activity during specific vigilance states over the $12 \mathrm{hr}$ light phase revealed minor differences in power spectral values $(1-32 \mathrm{~Hz}$ ) between the two groups of rats. EEG slow-wave activity (SWA; EEG power in the 1-5 Hz range), an indicator of sleep intensity (Borbély and Neuhaus, 1979), was evaluated during SWS2 across the light phase. SWA progressively decreased over consecutive $2 \mathrm{hr}$ intervals during the light phase, and the time course for this decrease was comparable in the two groups (Fig. 4). No differences in SWA levels or in power densi- ties within the higher frequency ranges $(5-32 \mathrm{~Hz})$ in any of the 2 hr intervals were observed between CONT and PNS rats (data not shown). During PS, similar power spectral values were obtained in PNS rats and CONT rats in the entire frequency range studied (1-32 Hz).

The only significant correlation between basal plasma corticosterone levels at 2 months of age and the measured sleep parameters at 3-4 months of age was a positive correlation with the total amount of PS during the $12 \mathrm{hr}$ light phase $(r=0.53 ; p=0.0365)$ as well as over the entire $24 \mathrm{hr}$ period of baseline sleep recording $(r=0.53 ; p=0.0356)$ (data not shown). The AUC for the stress-induced increase in corticosterone levels was also positively correlated with the $24 \mathrm{hr}$ amount of baseline PS ( $r=0.80 ; p=$ $0.0002)$, as was sleep fragmentation during the $12 \mathrm{hr}$ dark phase $(r=0.57 ; p=0.0224)$ (Fig. 5).

\section{Effects of $1 \mathrm{hr}$ restraint stress on sleep EEG and correlations with stress-induced corticosterone secretion}

During the second baseline sleep recording period ( $22 \mathrm{hr}$ instead of $24 \mathrm{hr}$ ), the sleep-wake patterns of all rats were similar to those obtained in the first recording session. Again, compared to CONT rats, PNS rats exhibited enhanced total PS time over the total $22 \mathrm{hr}$ period $(+32 \%$; $p=0.0001)$, which was caused by an increased number of PS episodes $(+28 \%$; $p=0.0131)$. The percentage of PS relative to total sleep time was increased as well $(+30 \% ; p<0.0001)$. Similarly, PNS rats spent significantly more time in SWS1 $(+66 \% ; p=0.0001)$ and showed increased sleep fragmentation during the dark phase when compared to CONT animals. Whereas in the initial baseline sleep recording session the total SW2 time was not different between the two groups, in the second baseline session there was a significant decrease in the total SWS2 time $(-13 \% ; p=0.004)$ during the light phase of PNS animals. The decrease of SWS2 was also observed during both the light and the dark phases when expressed as a percentage of total sleep time (data not shown).

The $1 \mathrm{hr}$ restraint stress resulted in long-lasting effects on PS in both groups of rats. Compared to their baseline values, CONT and PNS rats showed significantly increased amounts of PS during the remaining $10 \mathrm{hr}$ of light $(\mathrm{CONT},+16 \%, p=0.0006$; PNS, $+9 \%, p=0.0031)$ and the subsequent $12 \mathrm{hr}$ of dark (CONT, $+30 \%, p=0.0196 ;$ PNS, $+27 \%, p=0.0018)$. Although PS values were significantly higher in PNS rats compared to CONT rats during the light phase $(+21 \% ; p=0.0052)$ (Fig. 6, top), the relative stress-induced PS increase during the light phase was significantly less in PNS than in CONT rats $(p=0.0394)$ (Fig. 6, bottom). In both groups, EEG power spectral activities during PS were not affected by restraint stress.

The $1 \mathrm{hr}$ restraint stress resulted, in CONT rats only, in a moderate rebound increase of total SWS2 time limited to the first $2 \mathrm{hr}$ of recovery $(+20 \% ; p=0.0123)$ (Fig. 7, top ). In both groups, SWS2 intensity (indexed by SWA) was more affected than its duration. Indeed, EEG power density in the $1-5 \mathrm{~Hz}$ range was significantly increased above baseline during the three $2 \mathrm{hr}$ intervals after restraint, with a comparable magnitude in the two groups (Fig. 7, bottom). In response to the $1 \mathrm{hr}$ restraint, other abnormalities that characterized sleep in PNS rats under baseline conditions were still present during sleep recovery, i.e., total SWS2 time decreased in the light phase $(-15 \% ; p=0.0001)$ whereas total SWS1 time $(+60 \% ; p<0.0001)$ and sleep fragmentation $(+20 \% ; p=0.0265)$ increased during the dark phase.

A number of significant correlations were found between the 

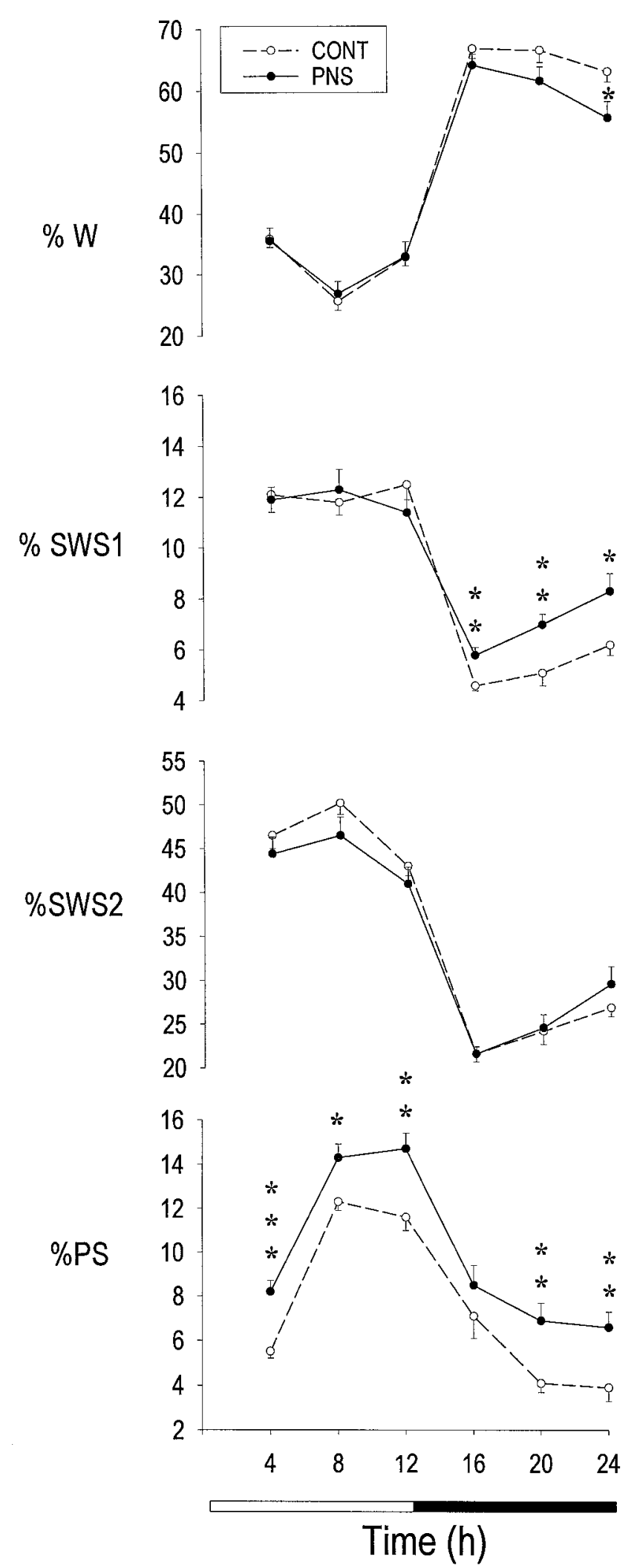

Figure 2. Distribution per $4 \mathrm{hr}$ intervals of vigilance states in eight control (CONT) and eight prenatally stressed (PNS) rats under baseline conditions. Mean ( \pm SEM) values of wake $(W)$, light slow-wave sleep $(S W S 1)$, deep slow-wave sleep (SWS2), and paradoxical sleep $(P S)$ are expressed as percentage of recording time. ${ }^{*} p<0.05$; ${ }^{*} p<0.01$; ${ }^{* * *} p<$ 0.001 (two-tailed unpaired Student's $t$ test) for between-groups comparisons.
Table 1. Total duration of each vigilance state during the light (0-12 hr) and dark phase (12-24 hr) in control and prenatally stressed rats

Baseline vigilance states

\begin{tabular}{lrcc}
\hline & & Control & Prenatal stress \\
\hline W (min) & $0-12 \mathrm{hr}$ & $226.8 \pm 6.9$ & $229.2 \pm 13.5$ \\
& $12-24 \mathrm{hr}$ & $471.3 \pm 5.4$ & $434.7 \pm 7.1^{* *}$ \\
SWS1 (min) & $0-12 \mathrm{hr}$ & $87.3 \pm 2.2$ & $85.5 \pm 3.4$ \\
& $12-24 \mathrm{hr}$ & $38.2 \pm 1.8$ & $50.8 \pm 2.4^{* * *}$ \\
SWS2 (min) & $0-12 \mathrm{hr}$ & $335.3 \pm 6.2$ & $316.4 \pm 12.7$ \\
& $12-24 \mathrm{hr}$ & $174.5 \pm 5.0$ & $181.9 \pm 5.6$ \\
PS (min) & $0-12 \mathrm{hr}$ & $70.6 \pm 2.0$ & $89.0 \pm 3.1^{* * *}$ \\
& $12-24 \mathrm{hr}$ & $36.1 \pm 2.4$ & $52.6 \pm 3.5^{* *}$ \\
\% SWS1/TST & $0-12 \mathrm{hr}$ & $17.7 \pm 0.5$ & $17.5 \pm 0.9$ \\
& $12-24 \mathrm{hr}$ & $15.4 \pm 0.7$ & $17.8 \pm 0.9$ \\
\% SWS2/TST & $0-12 \mathrm{hr}$ & $67.9 \pm 0.4$ & $64.3 \pm 0.9^{* *}$ \\
& $12-24 \mathrm{hr}$ & $70.2 \pm 1.0$ & $64.0 \pm 1.2^{* *}$ \\
\% PS/TST & $0-12 \mathrm{hr}$ & $14.3 \pm 0.4$ & $18.2 \pm 0.6^{* * *}$ \\
& $12-24 \mathrm{hr}$ & $14.4 \pm 0.9$ & $18.3 \pm 1.0^{*}$
\end{tabular}

Mean ( \pm SEM) values $(n=8$ rats in each group) of W, SWS1, SWS2, and PS are expressed in minutes. SWS1, SWS2, and PS are also expressed as a percentage of total sleep time (TST).

${ }^{*} p<0.05 ;{ }^{* *} p<0.01 ;{ }^{* * *} p<0.001$ (two-tailed unpaired Student's $t$ test) for between-groups comparisons.

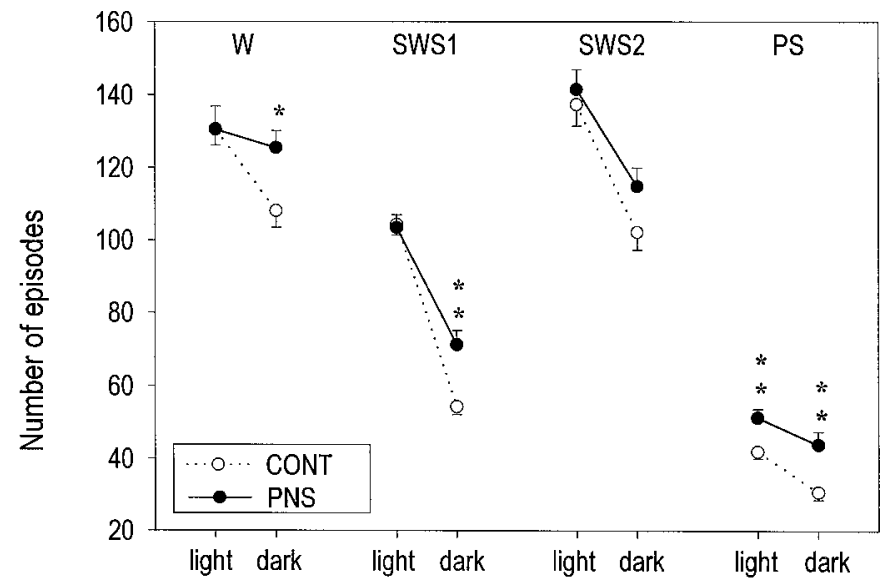

Figure 3. Mean ( \pm SEM) number of episodes for each vigilance state $(W, S W S 1, S W S 2, P S)$ during light or dark phases, in CONT and PNS rats under baseline conditions. ${ }^{*} p<0.05$; ${ }^{*} p<0.01$ (two-tailed unpaired Student's $t$ test) for between-groups comparisons.

AUC for stress-induced plasma corticosterone determined at 2 months of age and sleep-wake parameters at 3-4 months after an acute restraint stress. The amount of PS time over the $22 \mathrm{hr}$ recording period $(r=0.63 ; p=0.0096)$, as well as the amount of SWS1 time during the dark phase $(r=0.69 ; p=0.0030)$ and the number of episodes in each vigilance state during the dark phase $(r=0.58 ; p=0.0197)$ were all positively correlated with the AUC for corticosterone levels after acute restraint stress. In addition, stress-induced corticosterone levels were negatively correlated to the amount of SWS2 time $(r=-0.79 ; p=0.0003)$ during the light phase (Fig. 8). Thus, the stress-induced increase in corticosterone secretion revealed significant correlations with each sleep-wake parameter that was already altered under baseline conditions by prenatal stress. 

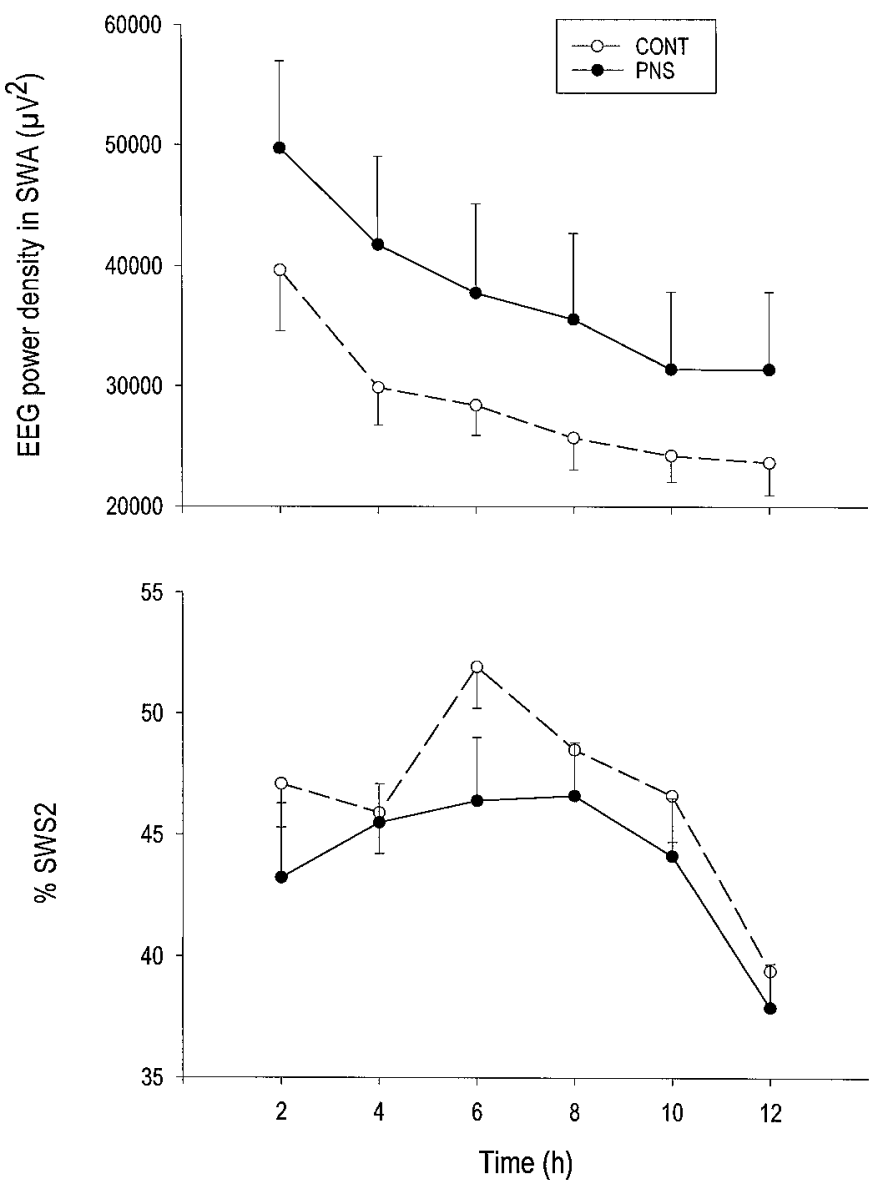

Figure 4. Top, Time course of mean ( \pm SEM) slow-wave activity (SWA) per $2 \mathrm{hr}$ intervals in SWS2 during light phase, in CONT and PNS rats under baseline conditions. SWA values are EEG power densities (square microvolts) averaged in the $1-5 \mathrm{~Hz}$ frequency band. Bottom, Corresponding mean $( \pm$ SEM $)$ values of SWS2 duration expressed as percentage of recording time.

\section{DISCUSSION}

The present results demonstrate that exposure to prenatal stress can produce long-term and selective changes in both the structure and the continuity of sleep. Although there are reports of abnormal "sleep-like behaviors" in PNS monkeys (Schneider, 1992) and PNS humans (Stott, 1973), our data provide the first polygraphic demonstration of long-term effects of prenatal stress on the sleep-wake cycle when the animals reach adulthood.

\section{Baseline conditions}

Under baseline conditions, sleep-wake alterations measured at the age of 3-4 months consisted primarily in an increase in PS duration at all phases of the light-dark cycle that was positively correlated to basal and stress-induced plasma corticosterone levels. Other sleep changes in PNS rats (i.e., increase in nighttime SWS1 and sleep fragmentation) were not correlated with basal corticosterone levels at the age of 2 months, suggesting that PS changes might represent a specific response to prenatal stressinduced changes in the HPA axis. The observation of larger PS amounts and a lower percentage of SWS2 relative to total sleep time in rats showing higher stress-induced corticosterone responses, further suggests an important role for the HPA axis in sleep regulation and its changes in response to prenatal stress. Interestingly, studies in humans have indeed suggested a role for

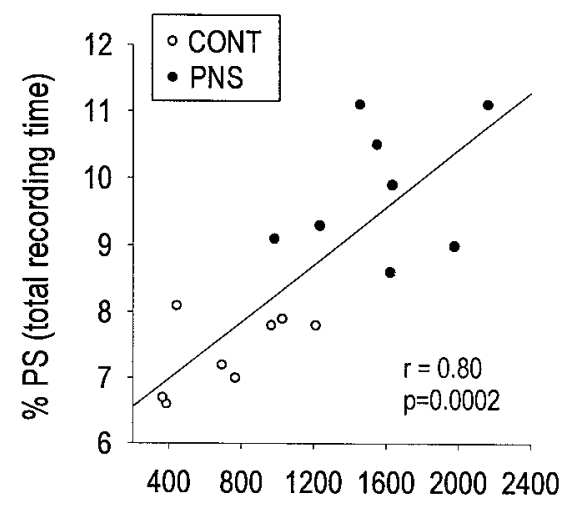

Total corticosterone (AUC)

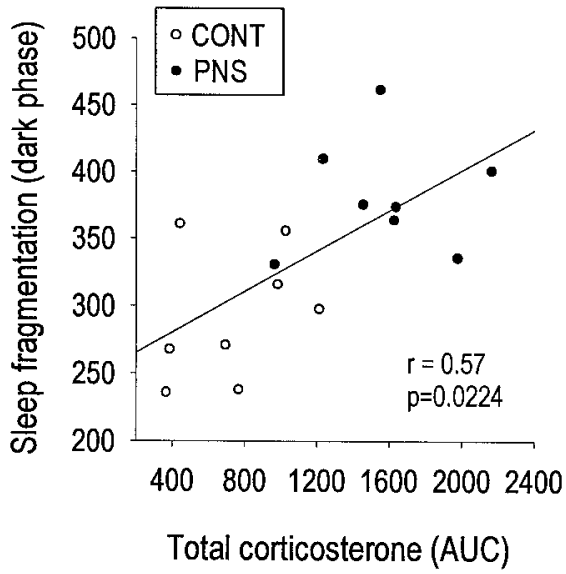

Figure 5. Positive correlations between individual stress-induced plasma corticosterone AUC values and amounts of PS expressed as percentage of total recording time (top) or sleep fragmentation in the dark phase (i.e., the number of episodes in each vigilance state) (bottom), in eight CONT and eight PNS rats. $r=$ coefficient of Pearson's correlation analysis.

glucocorticoids in the modulation of PS and a role for mineralocorticoids in the modulation of SWS2 (Born et al., 1991).

The finding that stress is often a predisposing factor in the development of depression (Sapolsky, 1996) has led to the hypothesis that stress-induced models of depression have construct validity (Rosenwasser and Wirz-Justice, 1997; Willner, 1997). Exposure of laboratory animals to chronic stressors at adult age can lead to PS abnormalities (i.e., PS increase, shorter PS latency). In all these models, only transient PS changes were found during or after stress. In both the learned helplessness (Adrien et al., 1991) and the intermittent foot shock paradigms (Kant et al., 1995), PS was increased only during the first day of recovery. In rats exposed to chronic mild stress, an increase in PS was only observed during the first day of stress recovery (Cheeta et al., 1997). Although an increase in PS was found after 2 weeks of chronic stress, the increase disappeared soon after stress termination (Moreau et al., 1995). Thus, persistence of PS alterations in rats exposed to stress in utero dramatically contrasts with the reversibility of those in the above-mentioned models. Interestingly, we have noted that even at 6 months of age, sleep-wake differences between PNS and CONT rats were still present (our unpublished data).

In addition to the major effects on PS, prenatal stress produced an increase in sleep fragmentation and in total SWS1 time re- 


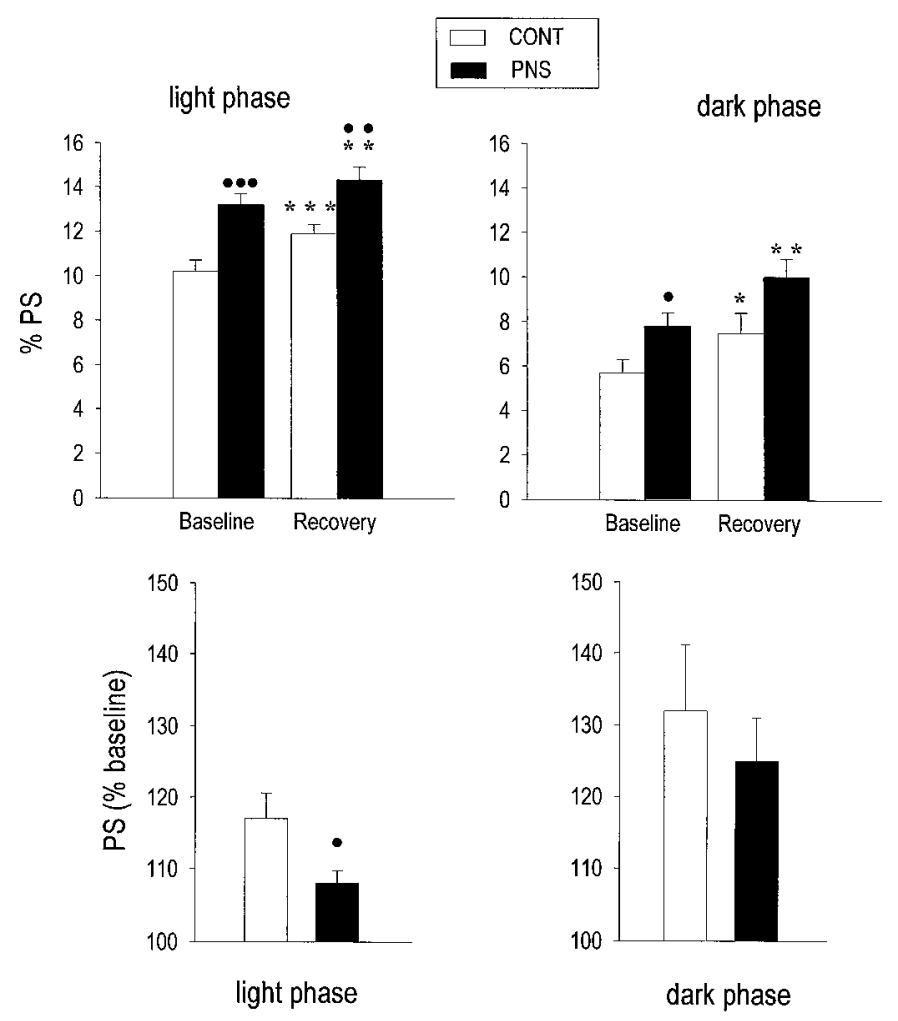

Figure 6. Amounts of PS during recovery from the $1 \mathrm{hr}$ restraint stress in CONT and PNS rats. Top, Mean ( \pm SEM) PS values (percentage of total recording time) under baseline and recovery conditions in the light (left panel) and the dark (right panel) phases. Under both baseline and recovery conditions, PNS rats had higher PS levels during the light phase compared to CONT rats $\left(\bullet p<0.05 ;{ }^{\bullet \bullet} p<0.01 ;{ }^{\bullet \bullet} p<0.001\right.$, two-tailed unpaired Student's $t$ test). During recovery sleep, a significant PS increase was observed in both groups during the light and the dark phase, as compared to their own baseline values $\left({ }^{*} p<0.05 ;{ }^{*} p<0.01\right.$; ${ }^{* * *} p<$ 0.001 ; two-tailed paired Student's $t$ test). Bottom, Mean ( \pm SEM) values of PS increase during recovery in the light and the dark phase are expressed as percentage of baseline values in each group. The magnitude of PS increase in the light phase was significantly lower in PNS compared to CONT rats ( $p=0.0234$; unpaired two-tailed Student's $t$ test).

stricted to the dark phase. SWS2 was decreased only when expressed as a percentage relative to total sleep time. A transient decrease in SWS2 has been reported in rats after 3 weeks of chronic mild stress (Cheeta et al., 1997).

\section{Acute restraint stress}

In response to an acute stress, there was an increase in total PS time in both groups of animals. A $1 \mathrm{hr}$ immobilization stress was previously found to be followed by an increase of sleep duration (mainly PS) when the acute stress was applied either at the beginning of the dark phase (Rampin et al., 1991) or during the light phase (Bouyer et al., 1997). It is tempting to speculate that the smaller percent increase over baseline during the light phase in the PNS group could be caused by an alteration of the PS response to stress in PNS rats. However, it could also reflect a ceiling effect because the baseline levels were already elevated in the PNS animals.

The $1 \mathrm{hr}$ restraint stress induced a compensatory effect on SWS2 duration only in CONT animals. Its magnitude was similar to that observed in other studies in response to either a $1 \mathrm{hr}$ restraint stress or sleep deprivation (Cespuglio et al., 1995; Bonnet et al., 1997). The failure of PNS animals to show a similar

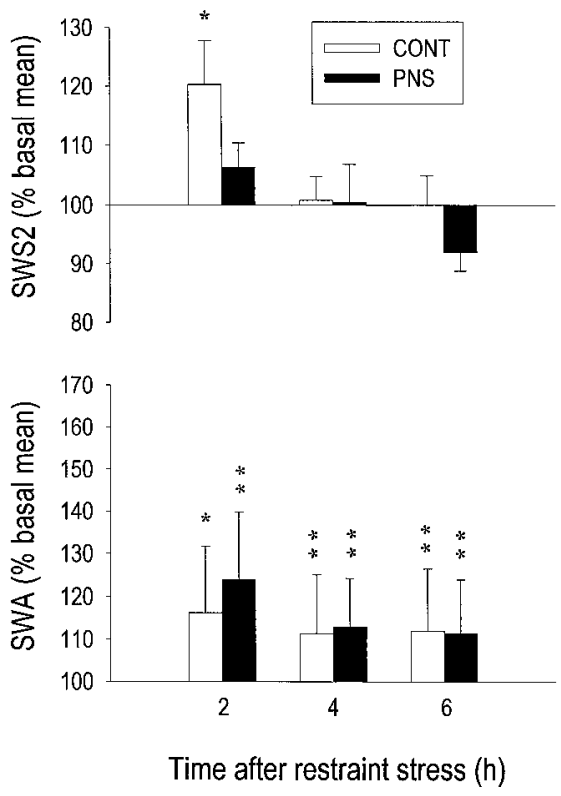

Figure 7. Effect of $1 \mathrm{hr}$ restraint stress on the amount of SWS2 and on SWA (EEG power in $1-5 \mathrm{~Hz}$ band) during SWS2, as measured during three consecutive $2 \mathrm{hr}$ intervals of recovery sleep in eight CONT and eight PNS rats. Mean values ( \pm SEM) of SWS2 or SWA are presented as a percentage of their corresponding baseline mean values. Both groups showed elevated SWA during the $6 \mathrm{hr}$ of analysis, whereas a significant increase in the amount of SWS2 was observed only in CONT rats during the first $2 \mathrm{hr}$ interval (* $p<0.05$; * $p<0.01$; paired two-tailed Student's $t$ test).

increase in SWS2 indicates a possible alteration in the SWS response, as does the decrease in SWS2 observed under the corresponding baseline conditions. In contrast, an increase in SWA, an index of sleep intensity, in response to restraint was observed in both groups. It should be noted that no increase in SWA was reported by others in response to a $3 \mathrm{hr}$ sleep deprivation (Tobler and Borbély, 1990), indicating that the increase observed in the present study was caused by the stress of the restraint procedure and not by any possible associated sleep loss. In support of this hypothesis is the finding of a similar increase in SWA in rats exposed to a $1 \mathrm{hr}$ social stress (Meerlo et al., 1997).

In response to acute stress, PNS rats show decreased binding capacity of hippocampal type I (mineralocorticoid) and type II (glucocorticoid) corticosteroid receptors (Henry et al., 1994; Maccari et al., 1995; Barbazanges et al., 1996). In view of the involvement of glucocorticoid and mineralocorticoid receptors in both SWS and PS (Friess et al., 1995), this desensitization could be related to the diminished response on PS and SWS2 after the acute stress challenge.

As shown previously, restraint stress leads to a rapid increase in plasma corticosterone (Henry et al., 1994), which in the present study was magnified at both the 20 and 60 min sampling time after the initiation of restraint. We also confirm here the previous finding that restraint stress can induce abnormally prolonged corticosterone secretion in PNS rats (Maccari et al., 1995; Barbazanges et al., 1996; Vallée et al., 1997). In the present study, significantly higher plasma corticosterone levels were found in PNS rats after 20 min of restraint, which were not observed in our previous studies in which rats were restrained for $30 \mathrm{~min}$ before blood sampling. These higher corticosterone levels might be explained by a different time course in plasma corticosterone levels, 


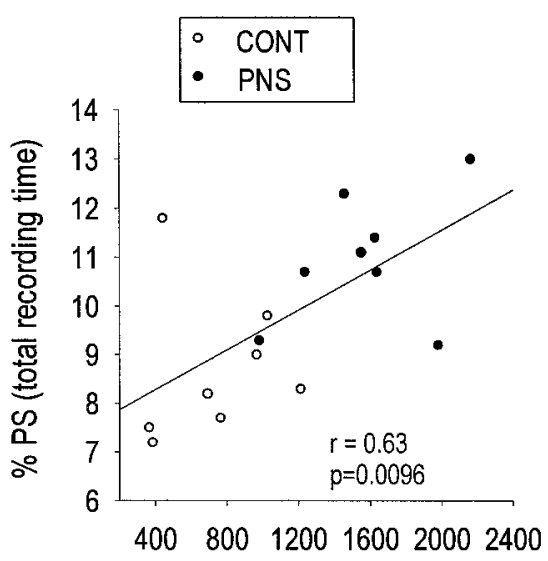

Figure 8. Correlations between stress-induced plasma corticosterone levels and sleep parameters during recovery from the $1 \mathrm{hr}$ restraint stress in eight CONT and eight PNS rats. Individual corticosterone AUC values (from 0 to $60 \mathrm{~min}$ after stress) were positively correlated to the amount of PS (top left panel), the amount of SWS1 in the dark phase (bottom left panel), and sleep fragmentation in the dark phase (bottom right panel). Individual corticosterone values were negatively correlated to the amount of SWS2 in the light phase (top right panel). Individual amounts of PS, SWS1, and SWS2 are expressed as percentage of recording time, and sleep fragmentation is expressed as number of episodes for each vigilance state. $r=$ coefficient of Pearson's correlation analysis.
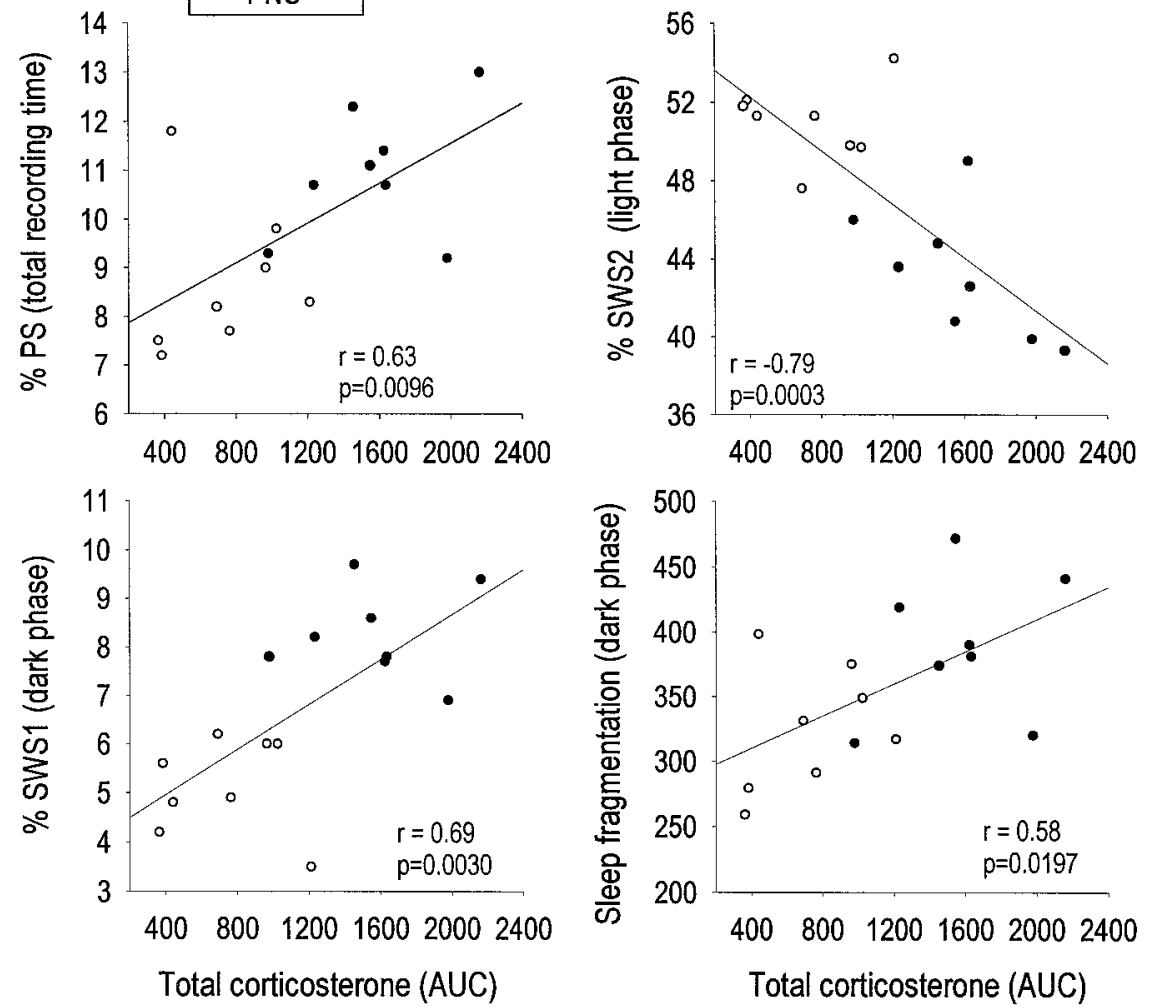

Total corticosterone (AUC) characterized by a steeper slope of corticosterone rise in response to stress. All sleep-wake differences between the two groups found under baseline conditions were still present during the 22 hr of sleep recording after restraint stress. Interestingly, after the $1 \mathrm{hr}$ restraint stress experiment, there were more robust correlations between plasma corticosterone levels (at the age of 2 months) and the various sleep parameters (at the age of 3-4 months) than under baseline conditions. In addition to the positive correlation between plasma corticosterone levels and total PS time or sleep fragmentation found under baseline conditions, in response to restraint, a positive correlation was also found with total SWS1 time in the dark phase and a negative one with total SWS2 time in the light phase. Taken together, these results indicate that high corticosterone levels can predict long-term and selective sleep-wake alterations in PNS rats.

In addition to glucocorticoids, other factors may be involved in the long-term effects of prenatal stress on sleep. Corticotropinreleasing hormone $(\mathrm{CRH})$ is involved in the regulation of physiological waking (Opp, 1995) and in sleep-wake modifications induced by acute stress exposure (Gonzalez and Valatx, 1997). Under stress conditions, CRH acting as a neurotransmitter in the locus coeruleus (LC) induces an increase in activity of noradrenergic neurons, which leads to an increase in PS (Gonzalez et al., 1996; Gonzalez and Valatx, 1997). Long-term alterations of CRH neurotransmission in PNS rats (Cratty et al., 1995) and developmental changes in their LC (Peters, 1984; Johnson et al., 1992) may explain the altered PS under baseline conditions. The serotonergic (5-HT) system may also be involved in the effects of prenatal stress on the adult sleep-wake cycle because exposure to high glucocorticoid levels or to acute stressors results in significant alterations in 5-HT turnover in the midbrain-pons area in
PNS rats, which also show long-term behavioral abnormalities and/or an altered response to 5-HT receptor agonists (Peters, 1988; Muneoka et al., 1997). In view of the permissive role played by the 5-HT system on PS regulation (Jouvet, 1984) and by a number of 5-HT receptors on sleep-wake modulation (for review, see Adrien, 1995; Boutrel et al., 1999), developmental alterations in brain 5-HT metabolism may contribute to PS modifications in PNS rats. In addition, during an acute restraint stress, adrenocorticotropin hormone and its derivatives, $\alpha$-melanocytestimulating hormone and corticotropin-like intermediate lobe peptide, released under the influence of the stress-induced 5-HT release might participate in the PS increase (Bonnet et al., 1997). A cholinergic component may be involved as well, as suggested by increased acetylcholine release after acute stress (Imperato et al., 1991; Kaufer et al., 1998). The cholinergic system is involved in the executive mechanisms of PS (Hobson et al., 1986), and recent data indicate that PNS rats have an acetylcholine hypersensitivity to CRH challenges (Day et al., 1998). Thus, permanent neurochemical changes in both monoaminergic (NA; 5-HT) and cholinergic systems might all participate in the PS modifications found in PNS rats.

Abnormalities in a variety of overt circadian rhythms have been documented in depressed patients, including rhythms of body temperature, various peripheral hormone concentrations, and urinary levels of neurotransmitter metabolites (Wehr and Goodwin, 1983). Circadian abnormalities include changes in freerunning period, amplitude, cohesion, and entrainment to photic and/or social "zeitgebers" (Wehr and Goodwin, 1983; Rosenwasser and Wirz-Justice, 1997). Interestingly, circadian timing disturbances have recently been reported in PNS rats that include an advanced acrophase in the rhythm of corticosterone secretion 
(Koehl et al., 1997), a phase advance in the rhythm of wheelrunning behavior (Koehl et al., 1999), a shortened free-running period of locomotor activity (Maccari et al., 1997), and an abnormal rate of resynchronization of the activity rhythm after abrupt shifts in the light-dark cycle (Van Reeth et al., 1998).

Alterations in sleep-wake patterns, a common biological trait of human depression, usually include a shortened latency of the first REM sleep episode, increased REM sleep amount and frequency during the first part of the night, decreased SWS amounts, and increased sleep fragmentation (Kupfer and Reynolds, 1992). Significant correlations between sleep abnormalities and dysfunctions of the HPA axis have been shown in depressed patients (Poland et al., 1992; Hubain et al., 1998) and may result from a stress component (Sapolsky, 1996; Rosenwasser and WirzJustice, 1997). In the present study in adult rats, sleep-wake changes resulting from prenatal stress were consistent with those described in depressed patients. Similarly, significant correlations between these sleep changes and corticosterone levels parallel those found in depression. Added to our previous findings in PNS rats of high anxiety and emotionality, dysfunction of the HPA axis, and circadian timing abnormalities, the observation of longterm changes in their sleep structure supports the validity of the "prenatal stress" model as a valid animal model of depression. The persistence of all induced abnormalities after stressor removal could be seen as being particularly advantageous for the design and testing of new therapeutical strategies in mood and sleep disorders.

\section{REFERENCES}

Adrien J (1995) Serotoninergic system and sleep-wakefulness regulation. In: The pharmacology of sleep. Handbook of Experimental Pharmacology, Vol 116 (Kales A, ed) pp 91-111. Berlin: Springer.

Adrien J, Dugovic C, Martin P (1991) Sleep-wakefulness patterns in the helpless rat. Physiol Behav 49:257-262.

Alonso SJ, Navarro E, Santana C, Rodriguez M (1997) Motor lateralization, behavioral despair and dopaminergic brain asymmetry after prenatal stress. Pharmacol Biochem Behav 58:443-448.

Barbazanges M, Piazza PV, Le Moal M, Maccari S (1996) Maternal glucocorticoid secretion mediates long-term effects of prenatal stress. J Neurosci 16:7783-7790.

Bonnet C, Léger L, Baubet V, Debilly G, Cespuglio R (1997) Influence of a $1 \mathrm{~h}$ immobilization stress on sleep states and corticotropin-like intermediate lobe peptide (CLIP or ACTH18-39, Ph-ACTH18-39) brain contents in the rat. Brain Res 751:54-63.

Borbély AA, Neuhaus HU (1979) Sleep deprivation: effects on sleep and EEG in the rat. J Comp Physiol 133:71-87.

Born J, de Kloet ER, Wenz H, Kern W, Fehm HL (1991) Gluco- and antimineralocorticoid effects on human sleep: a role of central corticosteroid receptors. Am J Physiol 260:E183-E188.

Boutrel B, Franc B, Hen R, Hamon M, Adrien J (1999) Key role of 5 -HT1B receptors in the regulation of paradoxical sleep as evidenced in 5-HT1B knock-out mice. J Neurosci 19:3204-3212.

Bouyer JJ, Deminière JM, Mayo W, Le Moal M (1997) Inter-individual differences in the effects of acute stress on the sleep-wakefulness cycle of the rat. Neurosci Lett 225:193-196.

Cespuglio R, Marinesco S, Baubet V, Bonnet C, El Kafi B (1995) Evidence for a sleep-promoting influence of stress. Adv Neuroimmunol 5:145-154.

Chapman R, Stern J (1979) Failure of severe maternal stress or ACTH during pregnancy to affect emotionality of male rat offspring: implications of litter effects for prenatal studies. Dev Psychobiol 12:255-269.

Cheeta S, Ruigt G, van Proosdij J, Willner P (1997) Changes in sleep architecture after chronic mild stress. Biol Psychiatry 41:419-427.

Cratty MS, Ward HE, Johnson E, Aazzaro AJ, Birkle DL (1995) Prenatal stress increases corticotropin-releasing factor (CRF) content and release in rat amygdala minces. Brain Res 675:297-302.

Day JC, Koehl M, Deroche V, Le Moal M, Maccari S (1998) Prenatal stress enhances stress- and corticotropin-releasing factor-induced stim- ulation of hippocampal acetylcholine release in adult rats. J Neurosci 18:1886-1892.

Deminière JM, Piazza PV, Guegan G, Abrous N, Maccari S, Le Moal M, Simon H (1992) Increased locomotor response to novelty and propensity to intravenous amphetamine self-administration in adult offspring of stressed mothers. Brain Res 586:135-139.

Dugovic C, Wauquier A, Leysen JE, Marrannes R, Janssen PA (1989) Functional role of 5-HT2 receptors in the regulation of sleep and wakefulness in the rat. Psychopharmacology 97:436-442.

Friess E, Windemann K, Steiger A, Lauer CJ, Holsboer F (1995) The hypothalamic-pituitary-adrenocortical system and sleep in man. Adv Neuroimmunol 5:11-125.

Gonzalez MC, Valatx JL (1997) Effects of intracerebroventricular administration of alpha-helical CRH (9-41) on the sleep/waking cycle in rats under normal conditions or after subjection to an acute stressful stimulus. J Sleep Res 6:164-170.

Gonzalez MC, Valatx JL, Debilly G (1996) Role of the locus coeruleus in the sleep rebound following two different sleep deprivation methods in the rat. Brain Res 740:215-226.

Henry C, Kabbaj M, Simon H, Le Moal M, Maccari S (1994) Prenatal stress increases the hypothalamo-pituitary-adrenal axis response in young and adult rats. J Neuroendocrinol 6:341-345.

Hobson JA, Lydic R, Baghdoyan HA (1986) Evolving concepts of sleep cycle generation: from brain centers to neuronal populations. Behav Brain Sci 9:371-448.

Holsboer F, Bardeleben U, Gerken A, Stalla GK, Muller OA (1984) Blunted corticotropin and normal cortisol response to human corticotropin-releasing-factor in depression. N Engl J Med 311:1127.

Hubain PP, Staner L, Dramaix M, Kerkhofs M, Papadimpitriou G, Mendlewicz J, Linkowski P (1998) The dexamethasone suppression test and sleep electroencephalogram in nonbipolar major depressed inpatients: a multivariate analysis. Biol Psychiatry 43:220-229.

Imperato A, Puglisi-Allegra S, Casolini P, Angelluci L (1991) Change in brain dopamine and acetylcholine release during and following stress are independent of the pituitary-adrenocortical axis. Brain Res 538:111-117.

Joffe JM (1978) Hormonal mediation of the effects of prenatal stress on offspring behavior. In: Studies in the development of behavior and the nervous system, pp 107-144. New York: Academic.

Johnson EO, Kamiralis TC, Chrousos GP, Ronda JM, Dyal CM, Czeisler CA (1992) Mechanisms of stress: a dynamic overview of hormonal and behavioral homeostasis. Neurosci Biobehav Rev 16:115-130.

Jouvet M (1984) Indolamines and sleep-inducing factors. In: Sleep mechanisms, Exp Brain Res, Vol 8 (Borbély AA, Valatx JL, eds), pp 81-94. Berlin: Springer.

Kant GJ, Pastel RH, Bauman RA, Meininger GR, Maughan KR, Robinson TN, Wright GR, Covington PS (1995) Effects of chronic stress in sleep. Physiol Behav 57:359-365.

Kaufer D, Friedman A, Seidman S, Soreqa H (1998) Acute stress facilitates long-lasting changes in cholinergic gene expression. Nature 393:373-377.

Koehl M, Barbazanges A, Le Moal M, Maccari S (1997) Prenatal stress induces a phase advance of circadian corticosterone rhythm in adult rats which is prevented by postnatal stress. Brain Res 759:317-320.

Koehl M, Dulluc J, Van Reeth O, Le Moal M, Maccari S (1999) Prenatal stress alters circadian activity of hypothalamo-pituitary-adrenal axis and hippocampal corticosteroid receptors in adult rats of both gender. J Neurobiol 40:302-315.

Kupfer DJ, Reynolds CF (1992) Sleep and affective disorders. In: Handbook of affective disorders, Vol 1 (Paykel ES, ed), pp 311-323. Edinburgh: Churchill Livingstone.

Maccari S, Piazza PV, Kabbaj M, Barbazanges A, Simon H, Le Moal M (1995) Adoption reverses the long term impairment in glucocorticoid feedback induced by prenatal stress. J Neurosci 15:110-116.

Maccari S, Koehl M, Le Moal M, Dulluc J, Olivares E, Van Reeth O (1997) Prenatal stress induces an advance of both corticosterone and locomotor activity rhythms in adult female rats. Soc Neurosci Abstr 23:1327.

Meerlo P, Pragt BJ, Daan S (1997) Social stress induces high intensity sleep in rats. Neurosci Lett 255:41-44.

Modell S, Yarroudis A, Huber J, Holsboer F (1997) Corticoid receptor function is decreased in depressed patients. Neuroendocrinology 65:216-222.

Moreau JL, Scherschlicht R, Jenck F, Martin JR (1995) Chronic mild stress- 
induced anhedonia model of depression: sleep abnormalities and curative effects of electroshock treatment. Behav Pharmacol 1995:682-687.

Muneoka K, Mikuni M, Ogawa T, Kitera K, Kamei K, Tagikawa M, Takahashi K (1997) Prenatal dexamethasone exposure alters brain monoamine metabolism and adrenocortical response in rat offspring. Am J Physiol 273:R1669-R1675.

Opp MR (1995) Corticotropin-releasing hormone involvement in stressor-induced alterations in sleep and in the regulation of waking. Adv Neuroimmunol 5:123-143.

Peters DA (1984) Prenatal stress: effect on development of rat brain adrenergic receptors. Pharmacol Biochem Behav 21:417-422.

Peters DA (1988) Effects of maternal stress during different gestational periods on the serotonergic system in adult rat offspring. Pharmacol Biochem Behav 31:839-843.

Plotsky PM, Owens MJ, Nemeroff CB (1998) Psychoneuroendocrinology of depression. Hypothalamic-pituitary-adrenal axis. Psychiatr Clin North Am 21:417-427.

Poland RS, Mc Cracken JM, Lutchmansingh P, Tondo L (1992) Relationship between REM sleep latency and nocturnal cortisol concentrations in depressed patients. J Sleep Res 1:54-57.

Porsolt RD, Le Pichon M, Jalfre M (1977) Depression: a new animal model sensitive to antidepressant treatments. Nature 266:730-732.

Rampin C, Cespuglio R, Chastrette N, Jouvet M (1991) Immobilisation stress induces a paradoxical rebound in rat. Neurosci Lett 126:113-118.

Rosenwasser A, Wirz-Justice A (1997) Circadian rhythms and depression: clinical and experimental models. In: Physiology and pharmacology of biological rhythms, Vol 125 (Redfern PH, Lemmer B, eds), pp 457-486. Berlin: Springer.

Sapolsky RM (1996) Why stress is bad for your brain. Science 273:749-750.
Schneider ML (1992) Prenatal stress exposure alters postnatal behavioral expression under conditions of novelty challenge in Rhesus monkey infants. Dev Psychobiol 25:529-540.

Schwierin B, Borbély AA, Tobler I (1998) Sleep homeostasis in the female rat during the estrous cycle. Brain Res 811:96-104.

Stott DN (1973) Follow-up study from birth of the effects of prenatal stress. Dev Med Child Neurol 15:770-787.

Tobler I, Borbély AA (1990) The effect of 3-h and 6-h sleep deprivation on sleep and EEG spectra of the rat. Behav Brain Res 36:73-78.

Vallée M, Mayo W, Dellu F, Lemoal M, Simon H, Macari S (1997) Prenatal stress induces high anxiety and postnatal handling induces low anxiety in adult offspring: role of corticosterone. J Neurosci 17:2626-2636.

Van Reeth O, Koehl M, Weibel L, Lemoal M, Maccari S (1998) Effects of prenatal stress on circadian synchronization in adult rats. J Sleep Res 7:287.

Wehr TA, Goodwin FK (1983) Biological rhythms in manic-depressive illness. In: Circadian rhythms in psychiatry (Wehr TA, Goodwin FK, eds), pp 129-184. Pacific Grove, CA: Boxwood.

Weinstock M (1997) Does prenatal stress impair coping and regulation of hypothalamic-pituitary-adrenal axis? Neurosci Biobehav Rev 21:1-10.

Willner P (1997) Validity, reliability and utility of the chronic mild stress model of depression: a 10-year review and evaluation. Psychopharmacology 134:319-329.

Wirz-Justice A (1995) Biological rhythms in mood disorders. In: Psychopharmacology: the fourth generation of progress (Bloom FE, Kupfer DJ, eds), pp 999-1017. New York: Raven. 